\title{
A COMPARISON OF DIFFERENT RUBBER DAM SYSTEMS ON A DENTAL SIMULATOR
}

\begin{abstract}
Martin Kapitán, Zdeňka Šustová, Romana Ivančaková, Jakub Suchánek
Charles University in Prague, Faculty of Medicine in Hradec Králové, and University Hospital Hradec Králové, Czech Republic: Department of Dentistry

Summary: The purpose of this study was to test the hypothesis that more recently developed rubber dam systems (Op$\operatorname{traDam}^{\circledR}$ Plus and OptiDam ${ }^{\mathrm{TM}}$ ) are faster and easier to handle, and that the quality of isolation is not decreased. The rubber dam systems were applied in standard conditions on a dental simulator in several model clinical situations. The time of preparation, application and removal were measured and the quality of isolation was evaluated. The median time of rubber dam placement was $51 \mathrm{~s}(\mathrm{Q} 1=38 \mathrm{~s}$; Q3 = $79 \mathrm{~s})$. The shortest median time of application was with OptiDam ${ }^{\mathrm{TM}}(42 \mathrm{~s})$, followed by a conventional rubber dam (53 s), and finally the longest was with OptraDam ${ }^{\circledR}$ Plus $(58 \mathrm{~s})$. The median volume of fluid remaining in the isolated space after 5 minutes was $9.5 \mathrm{~mL}(\mathrm{Q} 1=8 \mathrm{~mL} ; \mathrm{Q} 3=10 \mathrm{~mL})$. The largest median volume of remaining water was with OptiDam ${ }^{\mathrm{TM}}(10 \mathrm{~mL})$, followed by a conventional rubber dam $(9.5 \mathrm{~mL})$ and the least with OptraDam ${ }^{\circledR}$ Plus $(8.5 \mathrm{~mL})$. The afore-stated hypothesis about the advantages of modern rubber dam isolation systems was accepted for OptiDam ${ }^{\mathrm{TM}}$, but rejected for OptraDam ${ }^{\circledR}$ Plus. The results could contribute to decision-making concerning the choice of rubber dam system.
\end{abstract}

Key words: Dental equipment; Isolation; Operation field; Rubber dam

\section{Introduction}

One of the main functions of rubber dam is the isolation of the operation field from the environment of the oral cavity. These two compartments are divided by an elastic membrane with holes fitting to the cervices of isolated teeth. The quality of teeth isolation is important to prevent leakage in both directions $(1,2)$. The leakage of saliva or blood into the operation field negatively affects the properties of restorations. During root canal treatment this leakage can cause primary or repeated bacterial contamination of root canals. The leakage of all fluids used during the treatment (e.g. antiseptic solutions) may occur in the opposite direction. Of these fluids, sodium hypochlorite is the most dangerous because of its irritating and caustic effects. No study using fluid leakage through a rubber dam as a measure of the quality of isolation has been published in available literature.

The dentists who don't use rubber dam often comment on the difficulty and time consumption of this operation field isolation method as the reasons for not utilising it (3-7). From the onset, the choice of the rubber dam system can influence the training of work with the device. The conventional rubber dam introduced by Barnum almost 150 years ago is still considered cumbersome and time consuming by many dentists $(1,8)$, even though these opinions have been notably disputed in the literature $(7,9-11)$.
New rubber dam systems have been developed in recent years to facilitate and shorten the time of fixing and removing the appliance (12). The aim of this study was to compare three isolation systems to the basis of rubber dam (conventional rubber dam, OptraDam ${ }^{\circledR}$ Plus and OptiDam ${ }^{\text {TM}}$ ) with regards to time consumption and isolation quality. The authors tested the hypothesis that modern rubber dam systems are faster and easier to handle, and that the isolation quality is not decreased.

\section{Material and methods}

\section{Material and equipment}

The placement of rubber dam systems was carried out on the dental simulator (A-Dec Simulator, A-Dec ${ }^{\circledR}$, Newberg, Oregon, USA) with Frasaco jaws AG-3 (Frasaco, Tettnang, Germany) by three dentists who routinely use rubber dam on patients. The following rubber dam systems and application techniques were employed in this study:

- A conventional rubber dam consisting of latex membranes (Dental dams, thin, mint, Medesy ${ }^{\circledR}$, Maniago, Italy) and the basic set of instruments Fit Kofferdam ${ }^{\circledR}$ Starter Kit I (Hager \& Werken, Duisburg, Germany). The position of holes for isolated teeth was marked on the membrane according to the template. The membrane 
was perforated with a punch set to form holes of suitable sizes. A winged clamp was threaded into the hole for the anchor tooth and the membrane was attached to a frame. The clamp, frame and membrane were placed all at once onto the dental simulator using application forceps. Margins of the hole for the anchor tooth were pulled under the clamp wings, and the other holes in the membrane were adapted to the cervices of corresponding teeth using dental floss. Finally the membrane was stretched onto the frame (Fig. 1).

- OptraDam ${ }^{\circledR}$ Plus (Ivoclar Vivadent, Schaan, Lichtenstein). The membrane was perforated with a punch in pre-marked locations. OptraDam ${ }^{\circledR}$ Plus was placed onto the simulator according to the manual and the isolated teeth were passed through the holes using dental floss. In accordance with the manual, a Wedjets ${ }^{\circledR}$ stabilization cord (Coltène/Whaledent AG, Altstätten, Switzerland)

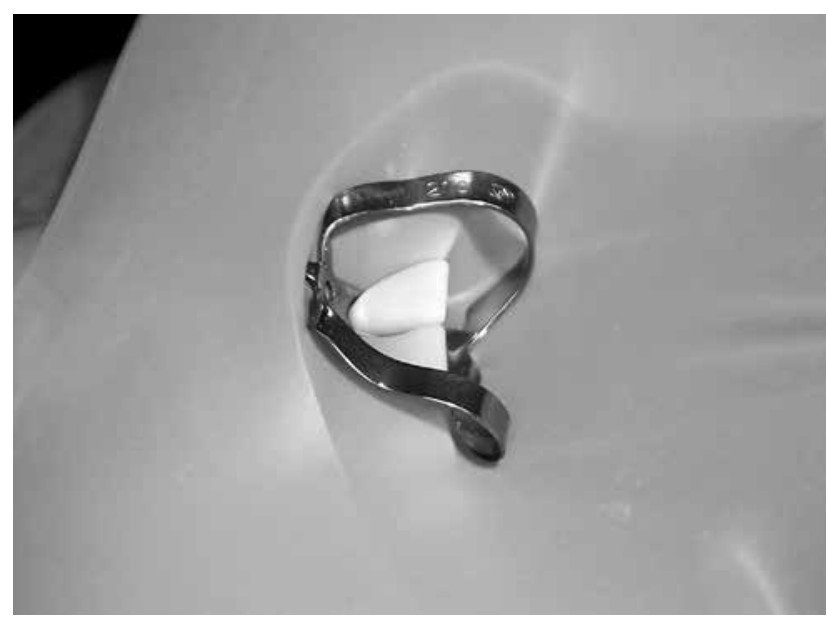

Fig. 1: The conventional rubber dam placed on the upper left permanent central incisor (situation 3).

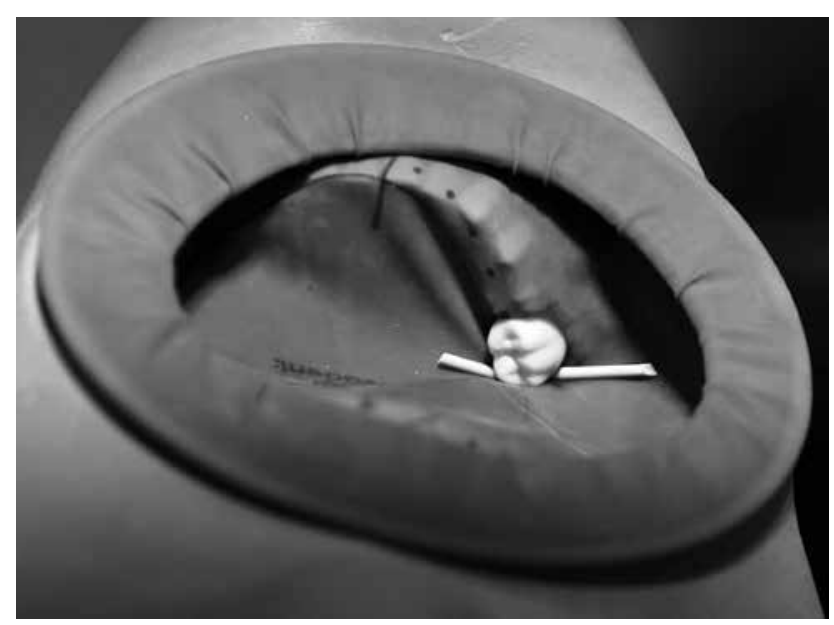

Fig. 2: OptraDam ${ }^{\circledR}$ Plus placed on the lower right permanent first molar (situation 2). was inserted into the interdental space behind the last isolated tooth to improve the retention of the membrane (Fig. 2).

- OptiDam ${ }^{\mathrm{TM}}$ (Kerr Hawe SA, Bioggio, Switzerland). The membrane was stretched onto the plastic frame and the holes were cut with scissors. OptiDam ${ }^{\mathrm{TM}}$ was placed onto the simulator, teeth were passed through the dam using dental floss and a metallic clamp was placed onto the anchor tooth according to the manual (Fig. 3).

\section{Methods}

The tested systems were compared in 6 model situations divided into two groups - isolation of a single tooth (situations 1-3) and isolation of a group of teeth (situations 4-6). The model situations were as follows:

1. Isolation of a single upper molar (the upper left permanent first molar).

2. Isolation of a single lower molar (the lower right permanent first molar).

3. Isolation of a single upper incisor (the upper left permanent central incisor).

4. Isolation of a group of upper lateral teeth (from the upper right first premolar to the upper right second permanent molar).

5. Isolation of the upper frontal segment including both first premolars.

6. Isolation of the lower dental arch between the both permanent first molars.

The position of the simulator was adjusted to imitate the supine position of a patient. The upper occlusal plane was angled 15 degrees backwards in relation to the vertical plane for the isolation of upper teeth in situations 1, 3, 4 and 5 (Fig. 4). The lower occlusal plane was angled 30 degrees above the horizontal plane for the isolation of lower teeth in situations 2 and 6 (Fig. 5).

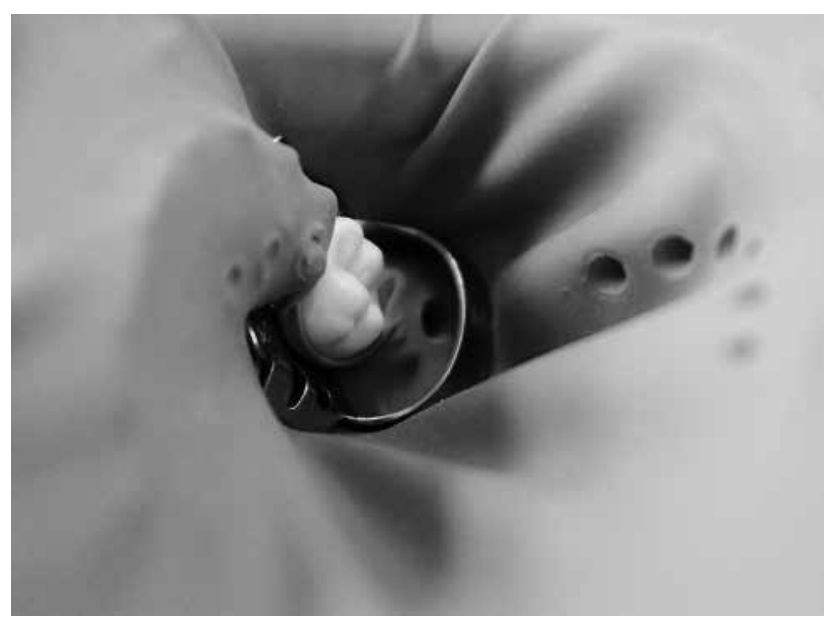

Fig. 3: OptiDam ${ }^{\mathrm{TM}}$ placed on the upper left permanent first molar (situation 1). 
Each dentist applied every rubber dam system ten times in each model situation; accordingly 540 single placements of rubber dams were performed. The following time periods were measured within seconds of accuracy for each placement:

- The time of rubber dam preparation.

- The time of rubber dam placement.

- The time of rubber dam removal.

An original method was developed by the authors to evaluate the quality of isolation. When the rubber dam had been placed, a volume of $10 \mathrm{~mL}$ of water was applied by syringe into the isolated space (Fig. 6-8). After a period of five minutes the remaining water was aspirated back into the syringe and the volume was determined to within an accuracy of $0.5 \mathrm{~mL}$. If all the water had leaked through the rubber dam, the time of occurence was noted. The volume of remaining water was thus considered the indicator of isolation quality.

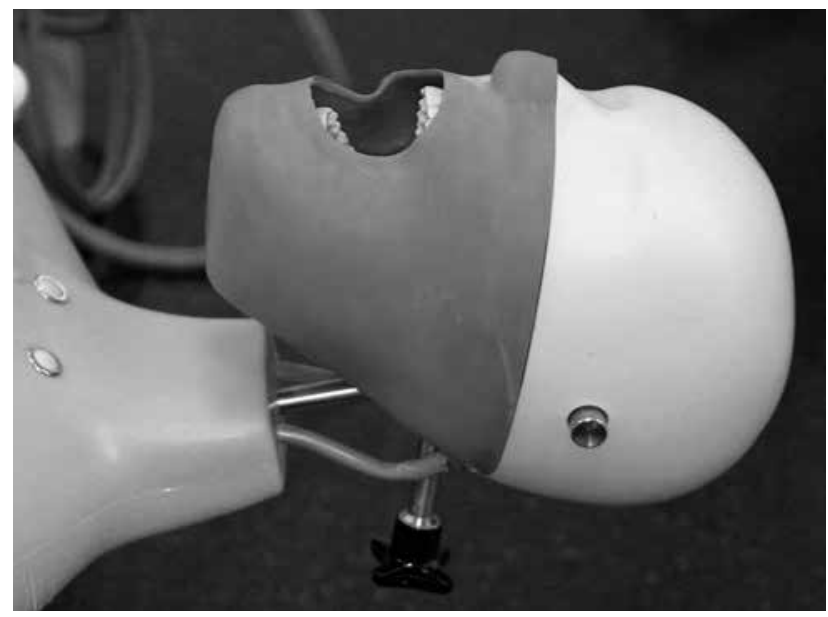

Fig. 4: The dental simulator in the position for work in the upper jaw.

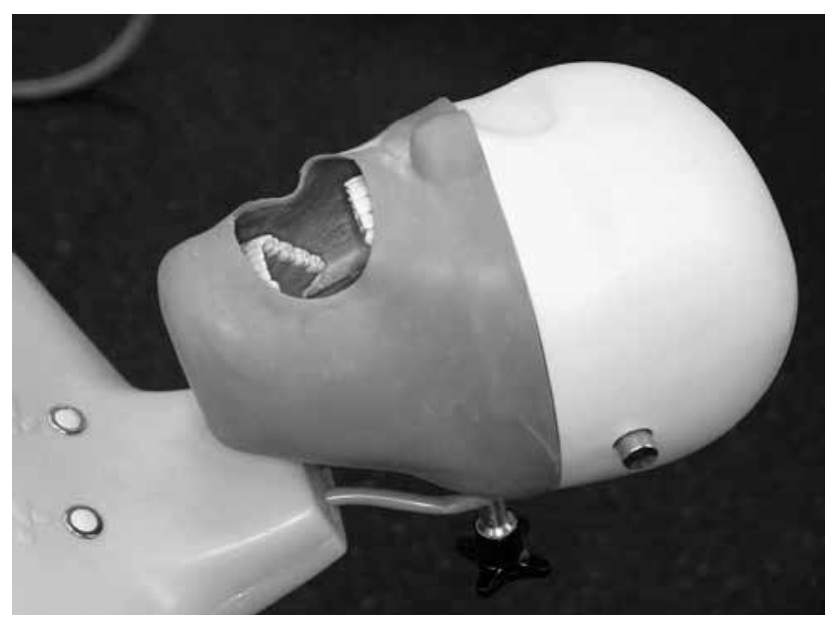

Fig. 5: The dental simulator in the position for work in the lower jaw.

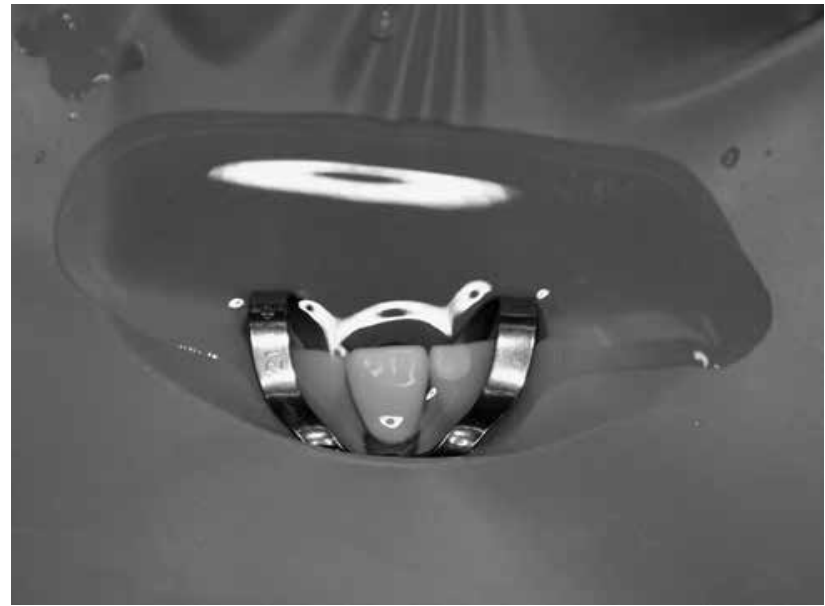

Fig. 6: The conventional rubber dam placed in the situation 3 with water in the isolated space.

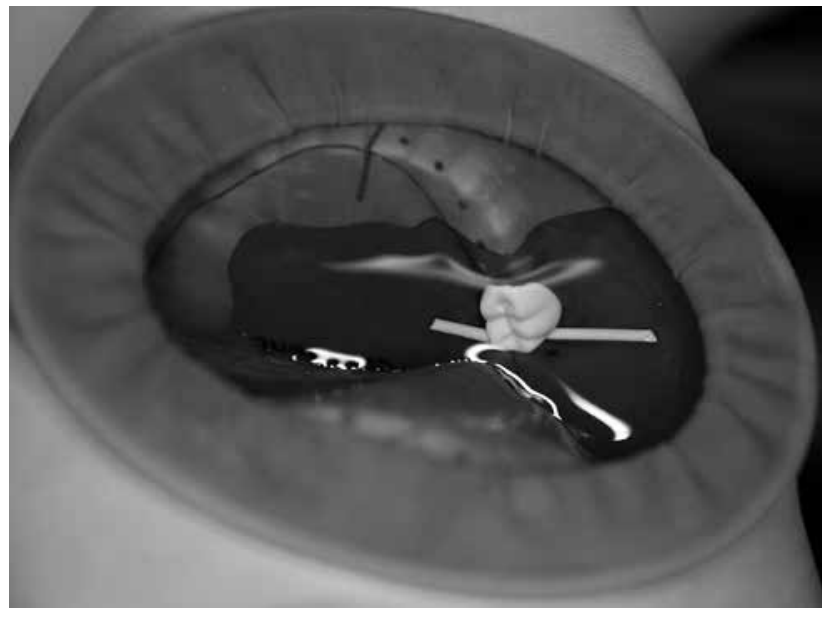

Fig. 7: OptraDam ${ }^{\circledR}$ Plus placed in the situation 2 with water in the isolated space.

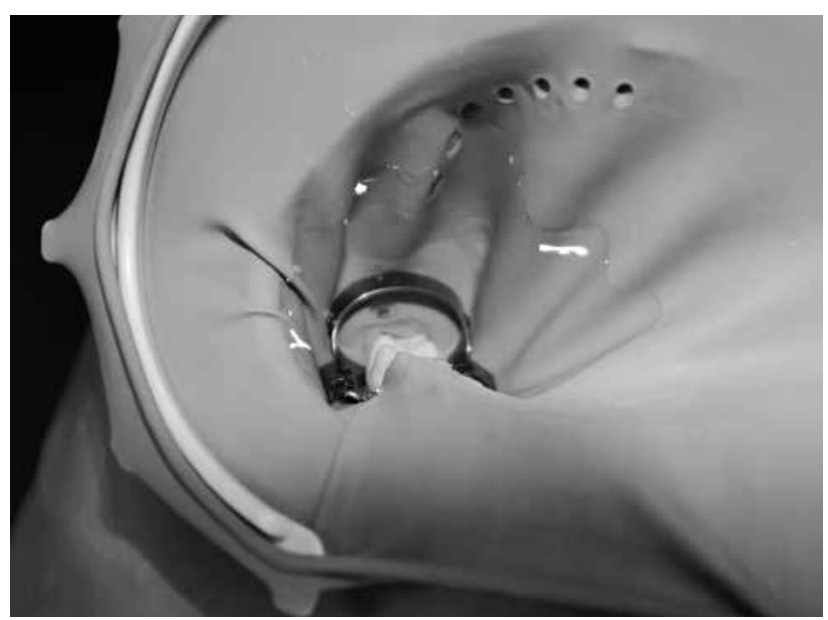

Fig. 8: OptiDam ${ }^{\mathrm{TM}}$ placed in the situation 1 with water in the isolated space. 


\section{Statistics}

The data obtained were statistically analyzed in NCSS 8 using methods of descriptive statistics (median, 1st quartile, 3rd quartile), Kolmogorov-Smirnov test and Kruskal-Wallis one way analysis with post hoc Dunn's test. Selected level of significance was $\alpha=0.05$.

\section{Results}

The obtained data regarding the times of rubber dam preparation, placement and removal and the volume of remaining water were not distributed normally, thus the median values are presented.

The differences between the dentists were not statistically significant in any of the observed parameters.

The median time of rubber dam preparation was $31 \mathrm{~s}$ $(\mathrm{Q} 1=24 \mathrm{~s} ; \mathrm{Q} 3=41 \mathrm{~s})$. The median values of preparation time for individual systems and quartiles are given in Table 1 . All the differences were statistically significant $(\mathrm{P}<0.001)$. The preparation time median values and quartiles for the different model situations are given in Table 2. The median preparation time was $26 \mathrm{~s}(\mathrm{Q} 1=19 \mathrm{~s}$; Q3 = $32 \mathrm{~s})$ for the isolation of a single tooth and $40 \mathrm{~s}(\mathrm{Q} 1=30 \mathrm{~s}$; Q3 $=49 \mathrm{~s})$ for the isolation of a group of teeth. The time of rubber dam preparation in the isolation of a single tooth was statistically significantly shorter than in the isolation of a group of teeth $(\mathrm{P}<0.001)$.

The median time of rubber dam placement was $51 \mathrm{~s}$ $(\mathrm{Q} 1=38 \mathrm{~s} ; \mathrm{Q} 3=79 \mathrm{~s})$. The median values of placement time for individual systems and quartiles are given in Table 1 . The differences between OptiDam ${ }^{\mathrm{TM}}$ and both conventional rubber dam and OptraDam ${ }^{\circledR}$ Plus were statistically significant $(\mathrm{P}<0.001)$. The difference between conventional rubber dam and OptraDam ${ }^{\circledR}$ Plus was not statistically significant. The median values and quartiles of time of rubber dam placement in the different model situations are given in Table 3. The median placement time was $38 \mathrm{~s}(\mathrm{Q} 1=34 \mathrm{~s}$; $\mathrm{Q} 3=44 \mathrm{~s})$ for the isolation of a single tooth and $78 \mathrm{~s}(\mathrm{Q} 1=62 \mathrm{~s}$; $\mathrm{Q} 3=95 \mathrm{~s}$ ) for the isolation of a group of teeth. The time of rubber dam placement in the isolation of a single tooth was statistically significantly shorter than in the isolation of a group of teeth $(\mathrm{P}<0.001)$.

The median time of rubber dam removal was $12 \mathrm{~s}$ $(\mathrm{Q} 1=9 \mathrm{~s} ; \mathrm{Q} 3=17 \mathrm{~s})$. The median values of removal time for individual systems and quartiles are given in Table 1. All

Tab. 1: A comparison of rubber dam systems.

\begin{tabular}{|l|c|c|c|c|}
\hline & $\begin{array}{c}\text { Preparation (s) } \\
\text { median (Q1; Q3) }\end{array}$ & $\begin{array}{c}\text { Placement (s) } \\
\text { median }(\mathrm{Q} 1 ; \mathrm{Q} 3)\end{array}$ & $\begin{array}{c}\text { Removal (s) } \\
\text { median }(\mathrm{Q} 1 ; \mathrm{Q} 3)\end{array}$ & $\begin{array}{c}\text { Isolation (mL) } \\
\text { median (Q1; Q3) }\end{array}$ \\
\hline Conventional & $40.5(34 ; 70)$ & $53.0(42 ; 83)$ & $12(9 ; 17)$ & $9.5(7.5 ; 10)$ \\
\hline OptraDam $^{\circledR}$ Plus & $21.5(18 ; 31)$ & $57.5(41 ; 92)$ & $14(10 ; 23)$ & $8.5(2.5 ; 10)$ \\
\hline OptiDam $^{\mathrm{TM}}$ & $28.5(25 ; 33)$ & $42.0(31 ; 68)$ & $10(8 ; 14)$ & $10.0(9.5 ; 10)$ \\
\hline
\end{tabular}

Tab. 2: A comparison of preparation time medians in different model situations.

\begin{tabular}{|l|c|c|c|c|c|c|}
\hline \multirow{2}{*}{} & \multicolumn{6}{|c|}{ Situation } \\
\cline { 2 - 7 } & $1(\mathrm{~s})$ & $2(\mathrm{~s})$ & $3(\mathrm{~s})$ & $4(\mathrm{~s})$ & $5(\mathrm{~s})$ & $6(\mathrm{~s})$ \\
\hline Conventional & $34(32 ; 35)$ & $32.5(31 ; 35)$ & $37.0(35 ; 40)$ & $42.0(41 ; 44)$ & $71.0(65 ; 74)$ & $76(72 ; 80)$ \\
\hline OptraDam $^{\circledR}$ Plus & $17(15 ; 18)$ & $19.0(18 ; 20)$ & $18.0(17 ; 19)$ & $24.5(23 ; 27)$ & $31.0(28 ; 35)$ & $44(41 ; 46)$ \\
\hline OptiDam $^{\mathrm{TM}}$ & $26(25 ; 28)$ & $25.0(23 ; 27)$ & $25.5(23 ; 28)$ & $30.5(26 ; 37)$ & $34.0(30 ; 40.5)$ & $34(33 ; 41)$ \\
\hline Common median $^{*}$ & $26(18 ; 32)$ & $25.0(20 ; 32)$ & $25.5(19 ; 35)$ & $31.0(25 ; 42)$ & $36.5(30 ; 65)$ & $45(38 ; 72)$ \\
\hline
\end{tabular}

The median times of preparation are given along with the 1 st and the 3 rd quartiles.

Tab. 3: A comparison of placement time medians in different model situations.

\begin{tabular}{|l|c|c|c|c|c|c|}
\hline & \multicolumn{5}{|c|}{ Situation } \\
\cline { 2 - 7 } & $1(\mathrm{~s})$ & $2(\mathrm{~s})$ & $3(\mathrm{~s})$ & $4(\mathrm{~s})$ & $5(\mathrm{~s})$ & $6(\mathrm{~s})$ \\
\hline Conventional & $37.5(35 ; 42)$ & $42.5(40 ; 47)$ & $45.0(40 ; 48)$ & $58.5(55 ; 65)$ & $84.0(76 ; 91)$ & $94.5(87 ; 108)$ \\
\hline OptraDam $^{\circledR}$ Plus & $43.0(38 ; 52)$ & $40.5(37 ; 50)$ & $41.0(36 ; 45)$ & $65.0(55 ; 76)$ & $90.5(82 ; 99)$ & $147.5(125 ; 164)$ \\
\hline OptiDam $^{\mathrm{TM}}$ & $34.0(29 ; 36)$ & $27.5(26 ; 32)$ & $31.5(29 ; 35)$ & $51.5(47 ; 59)$ & $62.5(56 ; 74)$ & $84.5(76 ; 96)$ \\
\hline Common median $^{*}$ & $37.0(35 ; 43)$ & $39.0(31 ; 45)$ & $39.0(33 ; 45)$ & $58.0(51 ; 68)$ & $82.5(68 ; 91)$ & $100.5(86 ; 130)$ \\
\hline
\end{tabular}

The median times of placement are given along with the 1 st and the 3 rd quartiles. 
Tab. 4: A comparison of isolation quality (remaining water volume medians) in different model situations.

\begin{tabular}{|l|c|c|c|c|c|c|}
\hline \multirow{2}{*}{} & \multicolumn{5}{|c|}{ Situation } \\
\cline { 2 - 7 } & $1(\mathrm{~mL})$ & $2(\mathrm{~mL})$ & $3(\mathrm{~mL})$ & $4(\mathrm{~mL})$ & $5(\mathrm{~mL})$ & $6(\mathrm{~mL})$ \\
\hline Conventional & $10(9.5 ; 10)$ & $10(5.5 ; 10)$ & $10.0(9.5 ; 10)$ & $9.0(3 ; 10)$ & $9.5(8 ; 9.5)$ & $7.5(2.5 ; 9.5)$ \\
\hline OptraDam $^{\circledR}$ Plus & $9(6.5 ; 9.5)$ & $10(10 ; 10)$ & $9.5(7.5 ; 9.5)$ & $4.5(1 ; 10)$ & $3.5(0.5 ; 8.5)$ & $5.0(2 ; 8)$ \\
\hline OptiDam $^{\text {TM }}$ & $10(10 ; 10)$ & $10(10 ; 10)$ & $10.0(10 ; 10)$ & $9.5(9.5 ; 10)$ & $9.5(9 ; 10)$ & $9.5(9 ; 10)$ \\
\hline Common median & $10(9.5 ; 10)$ & $10(9.5 ; 10)$ & $10.0(9.5 ; 10)$ & $9.5(7.5 ; 10)$ & $9.0(5.5 ; 9.5)$ & $8.0(4 ; 9.5)$ \\
\hline
\end{tabular}

The median volumes of remaining water are given along with the 1 st and the 3 rd quartiles.

the differences were statistically significant (conventional rubber dam vs. OptraDam ${ }^{\circledR}$ Plus $\mathrm{P}<0.01$; conventional rubber dam vs. OptiDam ${ }^{\mathrm{TM}} \mathrm{P}<0.05$; OptraDam ${ }^{\circledR}$ Plus vs. OptiDam $\left.^{\text {TM }} \mathrm{P}<0.001\right)$.

The median volume of remaining water was $9.5 \mathrm{~mL}$ $(\mathrm{Q} 1=8 \mathrm{~mL}$; $\mathrm{Q} 3=10 \mathrm{~mL})$. The median values of remaining water volume for individual systems are given in Table 1. All the differences were statistically significant $(\mathrm{P}<0.001)$. A comparison of isolation quality in different model situations is presented in Table 4. The median volume of remaining water was $10 \mathrm{~mL}(\mathrm{Q} 1=9.5 \mathrm{~mL} ; \mathrm{Q} 3=10 \mathrm{~mL})$ in the isolation of a single tooth and $9 \mathrm{~mL}(\mathrm{Q} 1=5 \mathrm{~mL}$; $3=9.5 \mathrm{~mL})$ in the isolation of a group of teeth. The quality of the isolation of a single tooth was statistically significantly better as compared with the isolation of a group of teeth $(\mathrm{P}<0.001)$. The leakage of the total amount of water occurred in 32 cases. The median time of complete leakage was $210 \mathrm{~s}(\mathrm{Q} 1=135 \mathrm{~s}$; $\mathrm{Q} 3=240 \mathrm{~s})$. With a conventional rubber dam complete leakage occurred 8 times, with the median time $165 \mathrm{~s}$. With OptraDam ${ }^{\circledR}$ Plus complete leakage took place 24 times, with the median time $210 \mathrm{~s}$. With OptiDam ${ }^{\mathrm{TM}}$ complete leakage did not occur at any time.

\section{Discussion}

Statistically significant differences were found when the systems OptraDam ${ }^{\circledR}$ Plus and OptiDam ${ }^{\mathrm{TM}}$ were compared with the conventional rubber dam. The conventional rubber dam was chosen as a control for comparing the newly developed isolation systems. The thin membrane of conventional rubber dam was used. The authors believed that it was easier to place a thinner membrane, thus it could serve better as a control, because one of the intended outcomes of this study was act as a form of recommendation regarding the easiness of the different isolation systems.

Concerning preparation, the conventional rubber dam showed the slowest result, undoubtedly because of the additional steps required for its preparation. The preparation of both modern rubber dam systems is simpler, as it is not necessary to mark the position of holes. The threading of the clamp is also a factor; a clamp is not used at all with OptraDam ${ }^{\circledR}$ Plus and it is placed separately after the ap- plication of OptiDam ${ }^{\mathrm{TM}}$. This parameter, however, is not really important clinically, because an extensive part of the preparation can be done before the patient arrives and thus does not prolong the treatment time.

The median time needed for rubber dam application on the simulator was less than one minute. We assume that the application of a rubber dam on a patient takes more time. The presence of surrounding structures makes it more difficult. The process can also be complicated by irregular morphology or position of teeth, or else by the impossibility of setting the patient's head to an optimal position. Nevertheless this time is rather short compared with the total time of treatment, which usually takes several dozen minutes. The statistically significant differences between OptiDam ${ }^{\mathrm{TM}}$ and both the other systems can be significant even clinically. The time needed for OptraDam ${ }^{\circledR}$ Plus placement was almost 1.5 times longer than the placement time for OptiDam ${ }^{\mathrm{TM}}$. It can be expected that these differences would be more considerable when these procedures are performed by dentists with less experience with rubber dam use or by students, as generally they require more time for rubber dam placement (9-11).

The ranking of the three systems in terms of the time of removal was the same as that of placement time. However, this parameter is not so important clinically, as the removal time was quite short in all the tested systems and so it did not have a great effect on the total manipulation time.

The best quality of isolation was achieved using OptiDam $^{\mathrm{TM}}$. The average isolation was achieved with the conventional rubber dam and the lowest level of isolation was with OptraDam ${ }^{\circledR}$ Plus. One limitation of the used method could lie in the fact that using a simulator does not entirely correspond with the circumstances in clinical practice, during which fluids are continually being suctioned from the isolated space and thus do not accumulate to such an extent.

Comparing the different model situations it was found that with the isolation of a single tooth there are shorter times of preparation, placement and removal. In addition the quality of isolation is better than with the isolation of a group of teeth. The shorter times are the result of the simpler manipulation when only one tooth is isolated. The differences in isolation quality are most likely caused by the 
occasional perforation of the membrane by the dental floss when passing the teeth through; this may account for the increased water leakage. The risk of increased water leakage is higher with the isolation of a group of teeth. Thus it might be recommended to isolate a single tooth or to decrease the number of isolated teeth, whenever possible in the clinical situation. On the other hand, if more teeth are isolated a better overview of the operation field as well as easier access to the teeth being treated is established.

According to Feierabend et al. (12), who compared the conventional rubber dam and OptraDam ${ }^{\circledR}$ in patients, the modern rubber dam systems are not necessarily better than the conventional rubber dam. A similar conclusion can also be drawn from our results. However, there are more criteria for the choice of isolation system than the parameters assessed in this study, such as obtaining references, the habitual practice of the workplace, the membrane material, system availability and price. The average prices of one piece of OptraDam ${ }^{\circledR}$ Plus or OptiDam ${ }^{\mathrm{TM}}$ are significantly higher than one membrane of conventional rubber dam.

\section{Conclusions}

The afore-stated hypothesis about the advantages of modern rubber dam isolation systems was accepted for OptiDam $^{\mathrm{TM}}$, but rejected for OptraDam ${ }^{\circledR}$ Plus. OptiDam ${ }^{\mathrm{TM}}$ showed a shorter manipulation time as well as better isolation quality compared with a conventional rubber dam. OptraDam ${ }^{\circledR}$ Plus proved to be less effective than the conventional rubber dam with regards to both of these parameters.

\section{Acknowledgements}

The authors would like to thank Dr. Eva Cermakova from Computer Technology Center, Charles University in Prague, Faculty of Medicine in Hradec Kralove, Czech Re- public, for help with statistical analysis, and Mr. Daniel Paul Sampey, MFA from the Department of English and American Studies, University of Pardubice, Czech Republic, for his help with the language revision of the article.

The study was financially supported by the Faculty of Medicine in Hradec Kralove internal competition grant $84029 / 2011$ and by the Charles University grant SVV-2011262904.

\section{Conflict of interest disclosure}

Conflicts of interest: none to declare. The authors declare that they are not associated in any way with the companies whose products were used in the study, and that there was no financial or other support from these companies.

\section{References}

1. Ahmad IA. Rubber dam usage for endodontic treatment: A review. Int Endod J 2009; 42: 963-72.

2. European Society of Endodontology. Quality guidelines for endodontic treatment: consensus report of the European Society of Endodontology. Int Endod J 2006; 39: 921-30.

3. Hill EE, Rubel BS. Do dental educators need to improve their approach to teaching rubber dam use? J Dent Educ 2008; 72: 1177-81.

4. Kapitan M, Sustova Z. The use of rubber dam among Czech dental practitioners. Acta Medica (Hradec Kralove) 2011; 54: 144-8.

5. Lynch CD, McConnell RJ. Attitudes and use of rubber dam by Irish general dental practitioners. Int Endod J 2007; 40: 427-32.

6. Slawinski D, Wilson S. Rubber Dam Use: A survey of pediatric dentistry training programs and private practitioners. Pediatr Dent 2010; 32: 64-8.

7. Whitworth JM, Seccombe GV, Shoker K, Steele JG. Use of rubber dam and irrigant selection in UK general dental practice. Int Endod J 2000; 33: 435-41.

8. Koshy S, Chandler NP. Use of rubber dam and its association with other endodontic procedures in New Zealand. N Z Dent J 2002; 98: 12-6.

9. Baltadjian H, Mahseredjian S. Time taken to position a rubber dam by fourth year dental students at the University of Montreal. J Can Dent Assoc 1992; 58: 228-9.

10. Filipović J, Jukić S, Miletić I, Pavelić B, Malčić A, Anić I. Patient's attitude to rubber dam use. Acta Stomatol Croat 2004; 38: 319-22.

11. Stewardson DA, McHugh ES. Patients' attitudes to rubber dam. Int Endod J 2002; 35: 812-9

12. Feierabend SA, Matt J, Klaiber B. A comparison of conventional and new rubber dam systems in dental practice. Oper Dent 2011; 36: 243-50.

Received: $14 / 04 / 2013$

Accepted in revised form: 04/12/2013

\section{Corresponding author:}

Martin Kapitán, University Hospital, Department of Dentistry, Sokolská 581, 50005 Hradec Králové, Czech Republic; e-mail: kapitanm@lfhk.cuni.cz 